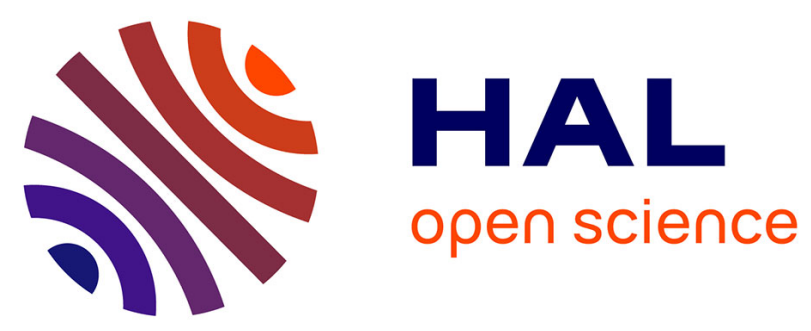

\title{
Does inhibitory control capacity in overweight and obese children and adolescents predict success in a weight-reduction program?
}

Ursula Pauli-Pott, Özgür Albayrak, Johannes Hebebrand, Wilfried Pott

\section{- To cite this version:}

Ursula Pauli-Pott, Özgür Albayrak, Johannes Hebebrand, Wilfried Pott. Does inhibitory control capacity in overweight and obese children and adolescents predict success in a weight-reduction program?. European Child and Adolescent Psychiatry, 2009, 19 (2), pp.135-141. 10.1007/s00787-009-0049-0 . hal-00535168

\author{
HAL Id: hal-00535168 \\ https://hal.science/hal-00535168
}

Submitted on 11 Nov 2010

HAL is a multi-disciplinary open access archive for the deposit and dissemination of scientific research documents, whether they are published or not. The documents may come from teaching and research institutions in France or abroad, or from public or private research centers.
L'archive ouverte pluridisciplinaire HAL, est destinée au dépôt et à la diffusion de documents scientifiques de niveau recherche, publiés ou non, émanant des établissements d'enseignement et de recherche français ou étrangers, des laboratoires publics ou privés. 


\title{
Does inhibitory control capacity in overweight and obese children and adolescents predict success in a weight-reduction program?
}

\author{
Ursula Pauli-Pott · Özgür Albayrak • \\ Johannes Hebebrand · Wilfried Pott
}

Received: 12 January 2009/Accepted: 16 July 2009/Published online: 31 July 2009

(C) Springer-Verlag 2009

\begin{abstract}
It has been assumed that inhibitory control capacity might influence the success of overweight or obese subjects in reducing weight. However, empirical research on this association is scarce. The present study, therefore, examines whether success in an outpatient weight-reduction program for children and adolescents can be predicted by pre-intervention inhibitory control capacity. The study sample consisted of 111 overweight and obese children and adolescents (7.5-15 years) who attended an outpatient weight-reduction program of 1 year's duration. Inhibitory control was assessed by two computerized neuropsychological procedures, a Go-NoGo and an interference task. Principal component analysis revealed "impulsivity" (fast but less valid reactions) and "inattention" (slow and highly variable reaction times) component. Those who succeeded in the intervention (losing more than $5 \%$ of BMI-SDS; $n=63$ ) scored significantly higher in the first component than those who failed, while controlling for pre-intervention BMI-SDS, age, gender, and maternal education level. The association was moderated by age. Although in younger children no effect was found, in adolescents high "impulsivity" predicted success. Our result supports the scant evidence for a role of inhibitory control. However, further studies are required to substantiate that
\end{abstract}

\footnotetext{
U. Pauli-Pott ( $\square)$

Institute of Medical Psychology, University Medical Centre, Justus-Liebig University of Giessen, Giessen, Germany

e-mail: ursula.pauli-pott@psycho.med.uni-giessen.de

Ö. Albayrak · J. Hebebrand

Department of Child and Adolescent Psychiatry,

University of Duisburg-Essen, Essen, Germany

W. Pott

Red Cross Children's Hospital Siegen, Siegen, Germany
}

weak inhibitory control, and thus high reactivity to external cues, entails a better outcome in behavior modification interventions.

Keywords Executive functions - Cognitive control . Obesity · Weight reduction program - Impulsivity . Inattention · Neuropsychological assessment

\section{Introduction}

The neuropsychological construct of inhibitory control refers to an individual's capacity to inhibit a pre-potent response provoked by an external cue [24, 25]. This capacity undergoes major developmental changes between early childhood and adolescence associated with the maturation of the prefrontal cortex (PFC) and its functional connectivity $[2,4,7,20]$. Social adjustment processes and the development of externalizing behavior problems have been found to be associated with the maturation of inhibitory control capacity $[8,19]$. In the context of humaneating behavior, Appelhans [3] recently pointed to the significance of PFC regions in inhibitory control over the appetitive motivational system and thus in dietary restraint behavior. Inhibitory control capacity is measured by (computerized) neuropsychological attentional tasks relying on paradigms that have been validated by neuroimaging methods and comparisons between patients with attention deficit/hyperactivity disorder (ADHD) and healthy controls. In the following, we thus refer exclusively to studies that used these paradigms.

It has been assumed that obese subjects show low inhibitory control capacity and also that this characteristic might lead to low adherence to weight-control interventions since low inhibitory control is associated with the 
resistance to change activities and an inability to modify previously learned behaviors [2]. From short-term observations in adults, it has been inferred that individuals with lower inhibitory control capacity are more likely to react to external cues and thus show a higher discrepancy between intended health behaviors and those actually conducted [12]. However, with respect to long-term observations of behavior changes in weight-reduction programs empirical research on this potential link is scant. To our knowledge, there is only one study that has analyzed whether inhibitory control predicts success in a weight-reduction program. Nederkoorn et al. [23] studied 26 overweight children who attended an outpatient intervention of 8-10 weeks of duration. Of these, 19 children completed the intervention and took part in follow-up examinations 6 and 12 months later. At baseline, inhibitory control was measured by a stop task procedure. Mean stop signal reaction time was significantly positively correlated with percentage overweight at all time points and was negatively correlated with the decrease of percentage overweight at the 6- and 12-month follow ups. Children with low inhibitory control thus showed less decrease in percentage overweight. This is a very interesting finding of potential practical relevance. However, a broader empirical basis is needed in order to draw any conclusions.

Our study, thus, examines the relationship between inhibitory control performance and success in a weightreduction program for overweight and obese children/ adolescents. It is expected that low inhibitory control predicts less weight reduction. Because inhibitory control capacity changes with age and also depends on the gender of the child/adolescent $[9,21,22]$, these characteristics are considered as co-variables. Furthermore, we control for maternal education level as an indicator of socioeconomic status of the family and presence versus absence of obese siblings in the family because in a previous analysis this characteristic turned out to be the best predictor of success in the weight reduction program [26].

\section{Methods}

\section{Participants}

Participants were 111 overweight and obese children. All children were referred to the outpatient weight-reduction program of the Red Cross Children's Hospital, Siegen, by local pediatric practices. Inclusion criteria were (1) body mass index (BMI) above the 95.0 age and sex related percentile or BMI above the 90.0 percentile if associated with obesity-related conditions (e.g. hypertension, dyslipidemia, and orthopedic problems), (2) intelligence quotient above 80 (CFT20; [31]), or at least school grades adequate for completion of basic education.

Mean BMI at the beginning of the intervention was 29.1 ( $\mathrm{SD}=4.7$, range 21.4-44.9) $\mathrm{kg} / \mathrm{m}^{2}$ and mean BMI-SDS was 2.43 ( $\mathrm{SD}=0.44$, range $1.31-3.54)$. Mean age of the children was 11.1 ( $\mathrm{SD}=2.0$, range $7.5-15.0$ years); 63 were girls. Of the mothers, one $(0.9 \%)$ did not finish school, $96(86.4 \%)$ attained basic educational or vocational qualifications, and $14(12.6 \%)$ had a high school or college qualification.

\section{Procedure}

The outpatient group intervention program for overweight and obese children and adolescents "Fit Kids" has been described in detail elsewhere [26]. As recommended by Summerbell et al. [28], "Fit Kids" includes behavioral modification of eating and physical activity behavior, physical exercise, and dietary training. The initial intervention phase lasts 3 months; the repetition and maintenance phase an additional 9 months. In the dietary training sessions, children learn to classify food according to content of fat, sugar, and protein, and learn how to create a more healthy diet (on the basis of the dietary guidelines of the German Nutrition Society). The physical activity course aims at rendering exercise enjoyable and developing a positive body attitude. Behavior modification of physical activity and eating behavior includes stimulus control and reward strategies and elements of cognitive behavioral therapy. The main topics are awareness and discrimination of hunger and appetite, self-analysis of physical activity behavior and goal setting, self-analysis of eating behavior and goal setting, impulse control strategies, social contacts and victimization, negative emotions and stress management. To facilitate transfer into everyday family life, parent training was conducted by the same psychologist and closely matched to the children's sessions. The program was conducted according to the program manual by an interdisciplinary team of clinical psychologists, nutritionists, and trainers.

Of the 111 children enrolled in the present study, 95 $(85.6 \%)$ completed the 1-year program. Reasons for dropping out were not enough time (12 cases), dissatisfaction with therapy ( 3 cases), and moving to another town (1 case). Neuropsychological assessments took place during the 3 weeks preceding the start of the program. Each child was tested by a research assistant in a quiet room between $3 \mathrm{pm}$ and $6 \mathrm{pm}$. Parents were interviewed and required to complete several questionnaires. The research was approved by the ethics committee for clinical research of the University Medical Centre, Giessen. All participants gave their written informed consent. 
Variables

\section{Body weight}

Body weight and height of the child were measured at the first meeting and then weekly throughout the entire program. Measurements were carried out by the same staff member using the same calibrated scale (digital column scale SECA 701) and wall-mounted stadiometer (SECA 222). Children were weighed in underwear. BMI was calculated and transformed into a standard deviation score on the basis of German reference data for children [16], using the least mean square method by Cole et al. [5], which normalizes the resulting distribution.

\section{Success in the weight-reduction program}

In the following, success is defined as a BMI-SDS reduction $\geq 5 \%$, non-response is defined as a BMI-SDS reduction of $<5 \%$ or dropping out (until break 8 of the dropouts gained weight of up to 4 kilos, seven showed no change and only one child lost weight). Of the 111 children/adolescents, 16 dropped out and 32 failed to reduce BMI-SDS by more than 5\%. Thus, 63 responders are compared with 48 non-responders.

\section{Co-variables}

Social and family data were assessed by a structured interview with mother, father, and child/adolescent conduced by a psychologist. Age and gender of child/adolescent and maternal education level are considered as co-variables. In the literature, maternal BMI has been found to be significantly associated with a child's success in reducing weight during weight-reduction treatment [27]. However, we previously found that the presence of obesity in siblings of the index child was a better predictor of failure to reduce overweight than parental BMI [26]. Obesity of siblings was assessed within the structured interview. Parents reported the weight and height of all children in the family; obesity was defined via a BMI $\geq 97$ th centile of the German reference population [16]. In the present sample, 15 children/adolescents had obese siblings. In the following, this variable also is considered as a co-variable.

\section{Inhibitory control}

For the assessment of inhibitory control capacity, two wellvalidated paradigms of differing complexity (involvement of working memory) [10] were used: a simple Go-NoGo procedure and a more complex interference task. Both tasks are subtests of the attention assessment battery
(Testbatterie zur Aufmerksamkeitsprüfung, TAP) [32]. The TAP is a computerized battery for the assessment of several specific attention functions. The Go-NoGo and incompatibility tasks were conducted in succession. The instructions appeared on the screen and were read to the child by the research assistant. To make sure that the child understood the instruction, each task was preceded by a short practice task.

Go-NoGo is a frequently used paradigm to assess inhibitory control $[15,24]$. The Go-NoGo task conducted here requires a response by pressing a button when an upright cross appears in the middle of the screen; the subject is instructed not to respond when instead of the upright cross an " $\mathrm{x}$ " appears. The reaction time score has been proved to discriminate significantly between children with ADHD and controls [9].

Similarly to the Stroop and Flancer paradigms, the child's capacity to resist interference and inhibit a preponderant response is measured by the incompatibility task. A short auditory warning signal is immediately followed by the appearance of an arrow on the left or the right side of a fixation point in the centre of the screen (duration $100 \mathrm{~ms}$ ). The child is instructed to press the right or left button depending on whether the arrow points right or left. Interference (incompatible trial) is given when the arrow appears in the one visual field but points in the opposite direction (requiring inhibition of the predominant tendency to press the button on the side the arrow appears). The task was run with 60 trials; $50 \%$ contained incompatible trials.

Validity of reaction time and variability of reaction time scores (standard deviation score) were demonstrated by showing significant differences between children with ADHD and matched healthy controls [6, 9, 29].

For each of the two tasks, three scores were considered: median and standard deviation of reaction times and number of valid reactions. To reduce the number of variables and to avoid redundant predictors, a principal component analysis was conducted. Two principle components explaining $58 \%$ of variance were extracted and Varimax rotated. Loadings of the variables on each component are depicted in Table 1. The first factor reflects fast but less valid reactions; the second factor reflects highly variable and slow reactions. The two components probably approximate two types of deficits distinguished by Drechsler et al. [6]: impairment in inhibition (high-error rate) related to hyperactivity/impulsivity, and increased variability in reaction times related to symptoms of inattention or an underlying activation problem. In the following, factor scores of the two components are used to indicate inhibitory control capacity. The two components are referred to as "impulsivity" and "inattention". 
Table 1 Principle components of inhibitory control scores

\begin{tabular}{lcc}
\hline & $\begin{array}{l}\text { Component I } \\
\text { "impulsivity" } \\
\text { loadings }\end{array}$ & $\begin{array}{l}\text { Component II } \\
\text { "inattention" } \\
\text { loadings }\end{array}$ \\
\hline GoNoGo & -0.74 & 0.24 \\
Median RT & 0.13 & 0.48 \\
Standard deviation RT & -0.54 & -0.21 \\
Valid reactions & & \\
Incompatibility & -0.62 & 0.65 \\
Median RT & 0.03 & 0.92 \\
Standard deviation RT & -0.77 & -0.23 \\
Valid reactions & 1.95 & 1.51 \\
\hline Eigenvalue & &
\end{tabular}

$R T$ reaction time

\section{Statistical analysis}

Logistic regression analysis was used to analyze whether the two inhibitory control components predict success in the weight reduction program over and above the age and gender of child/adolescent, maternal education level, presence versus absence of obese siblings and pre-intervention BMI-SDS. Because inhibitory control capacity develops far into adolescence and because this developmental process may differ in boys and girls [9, 21], we analyze whether the association between inhibitory control components and success is moderated by these co-variables. The procedure is as follows: in a first step all co-variables are introduced into the regression followed by the first and the second inhibitory control component. To test the moderator effects of age and gender, the interaction terms between each of the inhibitory control components and age and gender are introduced in four consecutive steps. Because regression coefficients are difficult to interpret when interactions are introduced [14], for each step "change statistics" ( $\chi^{2}$ change, $R^{2}$ change) are reported. These reflect the unique contribution to the prediction of each variable introduced.

In preliminary analyzes, we calculate the differences between the successful and unsuccessful patients in the co-variables and the correlations and partial correlations between co-variables and inhibitory control components.

\section{Results}

Association between co-variables and success in the weight reduction program

To reveal associations between the criterion variable and potential confounding variables, univariate differences in these variables between the successful and unsuccessful group were analyzed. Children who succeeded were significantly younger than those who did not $(t=2.96$, $P<0.01)$. Regarding gender of the child $\left[\chi^{2}(1)=0.77\right]$ and education level of mother $\left[\chi^{2}(2)=1.58\right]$, there were no statistically significant differences. The 15 children and adolescents with obese siblings showed a significantly lower success rate $\left[\chi^{2}(1)=9.55, P<0.005\right)$. The successful and unsuccessful groups did not differ in preintervention BMI-SDS $(t=0.86)$.

Associations between co-variables and inhibitory control components

Correlations and partial correlation coefficients between the co-variables and the two inhibitory control components are shown in Table 2. None of the co-variables was significantly correlated with the first component, while age and pre-intervention BMI-SDS were significantly associated with the second component, reflecting inattention (high variability and slow reaction times). The partial correlations show that independently of all other co-variables, younger age and higher pre-intervention BMI-SDS were associated with higher inattention.

\section{Prediction of success in the weight-reduction program}

Logistic regression analysis revealed that the first inhibitory control component significantly predicted success in the weight reduction program over and above the co-variables: age, gender, presence of obese siblings, maternal education level, and pre-intervention BMI-SDS of index child/adolescent. Children/adolescents who showed higher impulsivity (fast but less valid reactions) lost more weight, while those who showed slow but accurate reactions more likely failed in losing weight or dropped out. The amount of explained variance was $4 \%$. However, this association

Table 2 Correlations and partial correlations between co-variables and inhibitory control components

\begin{tabular}{|c|c|c|c|c|}
\hline & \multicolumn{2}{|c|}{$\begin{array}{l}\text { Component I } \\
\text { "impulsivity" }\end{array}$} & \multicolumn{2}{|c|}{$\begin{array}{l}\text { Component II } \\
\text { "inattention" }\end{array}$} \\
\hline & $r$ & $r_{\text {part }}$ & $r$ & $r_{\text {part }}$ \\
\hline Age & 0.07 & 0.07 & $-0.53 * * *$ & $-0.55 * * *$ \\
\hline Gender $^{\mathrm{a}}$ & 0.06 & 0.01 & $-0.19^{*}$ & -0.12 \\
\hline Maternal education level $^{\mathrm{a}}$ & 0.08 & 0.10 & -0.02 & 0.02 \\
\hline Presence of obese siblings ${ }^{\mathrm{a}}$ & 0.11 & 0.12 & -0.09 & -0.07 \\
\hline Pre-intervention BMI-SDS & 0.12 & 0.13 & $0.19 *$ & $0.31 * * *$ \\
\hline
\end{tabular}

$r$ correlation coefficient (apoint-biserial correlation), $r_{\text {part }}$ partial correlation between co-variable and inhibitory control component while controlling for the other co-variables

Significance $* P<0.10, * * * P<0.001$ 
Table 3 Result of the logistic regression analysis predicting child's responding versus non-responding in the weight reduction program

\begin{tabular}{|c|c|c|c|c|}
\hline Predictors entered into the regression & $\chi_{\text {change }}^{2}(d f) p$ & $R_{\text {change }}^{2}$ & $\chi_{\text {model }}^{2}(d f) p$ & $R_{\text {model }}^{2}$ \\
\hline $\begin{array}{l}\text { Step 1: Age of child/adolescent, gender of } \\
\text { child/adolescent, maternal education level, } \\
\text { presence of obese siblings, pre-intervention BMI-SDS }\end{array}$ & $16.76(5)<0.005$ & 0.20 & $16.76(5)<0.005$ & 0.20 \\
\hline Step 2: Impulsivity & $3.88(1)<0.049$ & 0.04 & $20.65(6)<0.002$ & 0.24 \\
\hline Step 3: Inattention & 0.02 (1) n.s. & 0.00 & $20.66(7)<0.004$ & 0.24 \\
\hline Step 4: Impulsivity $\times$ age & $9.62(1)<0.002$ & 0.10 & $30.28(8)<0.001$ & 0.34 \\
\hline Step 5: Impulsivity $\times$ gender & 0.31 (1) n.s. & 0.00 & $30.59(9)<0.001$ & 0.34 \\
\hline Step 6: Inattention $\times$ age & 0.12 (1) n.s. & 0.00 & $30.71(10)<0.001$ & 0.34 \\
\hline Step 7: Inattention $\times$ gender & 1.95 (1) n.s. & 0.02 & $32.66(11)<0.001$ & 0.36 \\
\hline
\end{tabular}

n.s. Not statistically significant

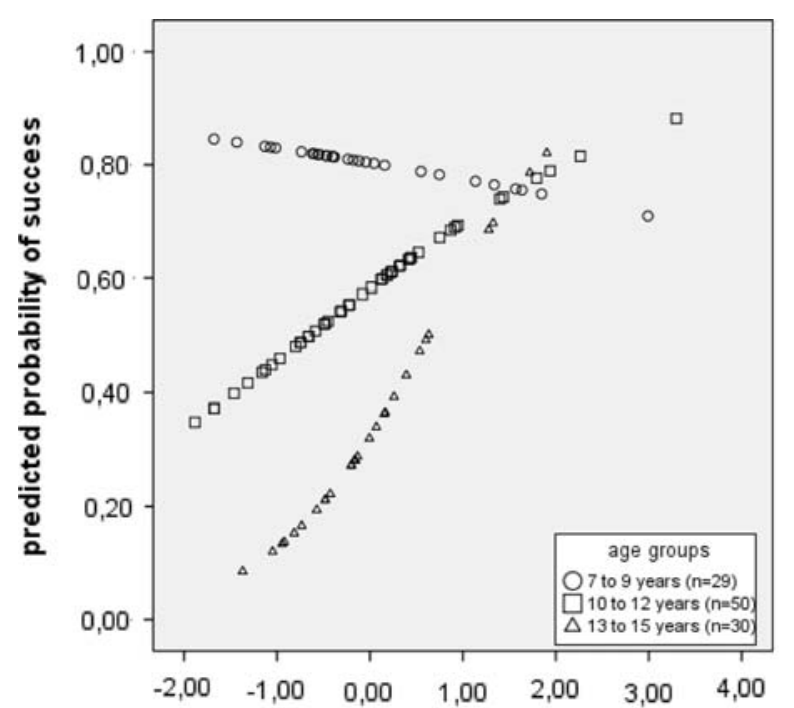

factor scores: "impulsivity" (fast, less valid reactions)

Fig. 1 Plot of the interaction between impulsivity (fast/ less valid reactions) and age on response to the weight-reduction program. Depicted are the predicted probability scores for success (To simplify the plot a separate regression was run without considering covariables and after transforming age into three categories.)

was qualified by a highly significant interaction with age, explaining $10 \%$ of variance in the criterion (Table 3). As depicted in Fig. 1, the association was more pronounced in adolescents than in younger children. The second inhibitory control component was not associated with success in the program nor were there any further significant interaction effects (Table 3 ).

\section{Discussion}

Success in our weight-reduction program was predicted by our first inhibitory control component (impulsivity); we observed a strong interaction with age: In the adolescent age range, response to the intervention was significantly predicted by this component of pre-intervention inhibitory control performance: those who succeeded in losing weight showed a pattern consisting of short reaction times combined with a high-error rate. This pattern could be interpreted as high impulsivity. The association was not present in the lower age range of the study group.

In a smaller-sized sample Nederkoorn et al. [23] found that children who showed "low impulsivity" as indicated by shorter stop signal reaction times, i.e. good capacity to suppress an ongoing reaction in response to a stop signal, lost more weight. Thus, the result of our study and that of Nederkoorn et al. seem contradictory. One reason may lie in age of participants. Nederkoorn et al. studied children with a mean age of 9.3 years $(S D=1.2)$, while the effect found in the present study was exclusively present in the teen agers.

Other possible reasons are the type and the duration of the intervention program conducted. Regarding the implementation of healthy eating behaviors Allan et al. [1] recently proposed several hypotheses to be tested in samples of young Scottish adults. Given the well established association between weak executive control and hyper responsivity to external rewarding cues (shape, smell of tasty food), the authors argue that on the one hand, individuals with executive control problems (measured by a battery of neuropsychological tasks) will show a higher discrepancy between intended and actual dietary behaviors (because their behavior is guided more by external stimuli); on the other hand, however, they will respond more to behavior modification strategies that use and control external cues to implement target behaviors. Their theses in part rely on Gollwitzer's work [11] on "implementation intentions." Here several experiments confirmed that high goal motivation coupled with implementation intention that link anticipated critical situations to goal directed responses (If-Then plans: whenever situation $\times$ arises, I will initiate response y) leads to an effective translation of intentions into action. Experiments with PFC-lesioned patients moreover suggested that individuals with 
executive control deficits might benefit even more from those strategies $[11,18]$. It seems possible, therefore, that adolescents with lower inhibitory control benefit more from the behavioral therapy techniques conducted in our weight-reduction program (principles of stimulus control, goal setting including behavior plans).

The elapsed time between the end of the intervention and the determination of success of the weight loss program might also be relevant: In the present study, children/ adolescents were assessed immediately after finishing the 12-month program. Nederkoorn et al. [23], however, found a strong association between low inhibitory control and BMI in follow-up examinations 6 and 12 months after finishing the treatment ( 8 weekly sessions). The authors assumed that the lack of inhibitory control probably contributes to a higher vulnerability to the temptations of tasty food, thus, making it difficult to stick to the diet and modified physical activity behavior. Low inhibitory control capacity might thus operate in two directions: easy response to ongoing therapy but problems with maintaining modified behavior. However, more research is needed to substantiate this interpretation. The ongoing follow-up examinations of the present study group may offer further clarification.

As mentioned, the two inhibitory control components used in the present study correspond to two types of deficits distinguished by Drechsler et al. [6] also on the basis of TAP [32] subtests: impairment in inhibition (mainly indicated by a high-error rate) and symptoms of inattention (mainly indicated by a high variability in reaction times). In the study by Drechsler et al. both measures significantly discriminated between ADHD patients and healthy controls indicating that both components capture neuropsychological deficits typical for ADHD. In the present study, however, the inattention component (highly variable/slow reactions) was not associated with subsequent weight reduction and, moreover, while this inattention component significantly correlated with pre-intervention BMI-SDS, the impulsivity component was not associated with this characteristic. These differential associations are difficult to interpret and thus should be taken as an indication of the need to further analyze the specific executive control components that are involved in the processes of weight (re-)gain and response to weight-control interventions.

Regarding the link between overweight/obesity and inhibitory control capacity in childhood several large-scale observations found overweight and obesity to be associated with self- and parent-reported ADHD symptoms [17, 30] and ADHD patients to show a mean BMI that exceeded the age- and gender-related reference data [13]. The association between pre-intervention BMI-SDS and the inattention component found in the present study thus may indicate that the association between increasing BMI and ADHD symptoms exists even within a group of overweight/obese children/adolescents and also on the basis of an objective neuropsychological measure.

The limitations of our study merit consideration: the effect size of the association between the impulsivity component and success is rather small. However, when age of child/adolescent is considered, about $10 \%$ of variance in success rates over and above the previously identified predictors can be explained. A further limitation lies in the lack of measures of eating and physical activity behaviors. Thus, we do not know by which behaviors the association between inhibitory control problems and success in reducing weight were mediated. In future research, these associations should be analyzed. Moreover, it would be informative to analyze the effects of the different components of weight reduction programs (i.e. behavior modification of eating and physical activity behavior, physical exercise, and dietary training) in controlled studies while considering inhibitory control performance as a moderator variable.

\section{References}

1. Allan J, Johnston M, Campbell N (2008) Why do people fail to turn good intentions into action? The role of executive control processes in the translation of healthy eating intentions into action in young Scottish adults. BMC Public Health 8:123

2. Anderson P (2002) Assessment and development of executive function (EF) during childhood. Child Neuropsychol 8:71-82

3. Appelhans BM (2009) Neurobehavioral inhibition of rewarddriven feeding: implications for dieting and obesity. Obesity 17:640-647

4. Brocki KC, Bohlin G (2004) Executive functions in children aged 6 to 13: a dimensional and developmental study. Dev Neuropsychol 26:571-593

5. Cole TJ (1990) The LMS method for constructing normalized growth standards. Eur J Clin Nutr 44:45-60

6. Drechsler R, Brandeis D, Földenyi M, Imhof K, Steinhausen H-C (2005) The course of neuropsychological functions in children with attention deficit hyperactivity disorder from late childhood to early adolescence. J Clin Psychol Psychiatry 46:824-836

7. Eigsti I-M, Zayas V, Mischel W, Shoda Y, Ayduk O, Dadlan MB, Davidson MC, Aber JL, Casey BJ (2006) Predicting cognitive control from preschool to late adolescence and young adulthood. Psychol Sci 17:478-484

8. Ellis LK, Rothbart MK, Posner MI (2004) Individual differences in executive attention predict self-regulation and adolescent psychosocial behaviors. Ann N Y Acad Sci 1021:337-340

9. Földenyi M, Imhof K, Steinhausen H-C (2000) Klinische Validität der computerunterstützten TAP bei Kindern mit Aufmerksamkeitsdefizit-/Hyperaktivitätsstörungen. Zeitschr f Neuropsychologie 11:154-167

10. Garon N, Bryson SE, Smith IM (2008) Exekutive function in preschoolers: a review using an integrative framework. Psychol Bull 134:31-60

11. Gollwitzer PM (1999) Implementation intentions: strong effects of simple plans. Am Psychol 54:493-503 
12. Hall PA, Fong GT, Epp LJ, Elias LJ (2008) Executive function moderates the intention-behavior link for physical activity and dietary behavior. Psychol Health 23:309-326

13. Holtkamp K, Konrad K, Müller B, Heussen N, Herpertz S, Herpertz-Dahlmann B, Hebebrand J (2004) Overweight and obesity in children with attention-deficit/hyperactivity disorder. Int J Obes 28:685-689

14. Hupfeld J (1999) Logistische regression. Eine Einführung. Institut für Sozialpsychologie, Universität Bern, Bern

15. Koschack J, Kunert HJ, Derichs G, Weniger G, Irle E (2003) Impaired and enhanced attentional function in children with attention deficit/hyperactivity disorder. Psychol Med 33:481-489

16. Kromeyer-Hauschild K, Wabitsch M, Kunze D, Geller D, Geiss HC, Hesse V, von Hippel A, Jaeger U, Johnsen D, Korte W, Menner K, Muller G, Muller JM, Niemann-Pilatus A, Remer T, Schaefer F, Wittchen HU, Zabransky S, Zellner K, Ziegler A, Hebebrand J (2001) Percentiles of body mass index in children and adolescents evaluated from different regional German studies. Monatsschrift Kinderheilkunde 149:807-818

17. Lam LT, Yang L (2007) Overweight/obesity and attention deficit and hyperactivity disorder tendency among adolescents in China. Int J Obes 31:584-590

18. Lengfelder A, Gollwitzer PM (2001) Reflective and reflexive action control in patients with frontal brain lesions. Neuropsychology 15:80-100

19. Lengua LJ (2002) The contribution of emotionality and selfregulation to the understanding of children's response to multiple risk. Child Dev 73:144-161

20. Luciana M, Conklin HM, Hooper CJ, Yarger RS (2005) The development of nonverbal working memory and executive control processes in adolescents. Child Dev 76:697-712

21. Manly T, Anderson V, Nimmo-Smith I, Turner A, Watson P, Robertson IH (2001) The differential assessment of children's attention: the test of everyday attention for children (TEA-Ch), normative sample and ADHD performance. J Child Psychol Psychiatry 42:1065-1081
22. Mezzacappa E (2004) Alerting, orienting, and executive attention: developmental properties and sociodemographic correlates in an epidemiological sample of young, urban children. Child Dev 75:1373-1386

23. Nederkoorn C, Jansen E, Mulkens S, Jansen A (2006) Impulsivity predicts treatment outcome in obese children. Behav Res Ther 45:1071-1075

24. Nigg JT (2005) Neuropsychological theory and findings in attention-deficit/hyperactivity disorder: the state of the field and salient challenges for the coming decade. Biol Psychiatry 57: $1424-1435$

25. Nigg JT (2000) On inhibition/disinhibition in developmental psychopathology: views from cognitive and personality psychology and a working inhibition taxonomy. Psychol Bull 126: 220-246

26. Pott W, Albayrak Ö, Hebebrand J, Pauli-Pott U (2008) Treating childhood obesity: family background variables and the child's success in a weight-control intervention. Int J Eat Disord (in press)

27. Reinehr T, Brylak K, Alexy U, Kersting M, Andler W (2003) Predictors to success in outpatient training in obese children and adolescents. Int J Obes Relat Metab Disord 27:1087-1092

28. Summerbell CD, Ashton V, Campbell KJ, Edmunds L, Kelly S, Waters E (2003) Interventions for treating obesity in children. Cochrane Database Syst Rev 2003:Art.No.: CD001872

29. Tucha O, Walitza S, Mecklinger L, Sontag T-A, Kübber S, Linder M, Lange KW (2006) Attentional functioning in children with ADHD-predominantly hyperactive-impulsive type and children with ADHD-combined type. J Neural Transm 113: 1943-1953

30. Waring E, Lapane KL (2008) Overweight in children and adolescents in relation to attention-deficit/hyperactivity disorder: results from a national sample. Pediatrics 122:e1-e6

31. Weiss RH (1998) Grundinteligenztest Skala 2 (CFT20). Hogrefe, Göttingen

32. Zimmermann P, Fimm B (2002) Testbatterie zur Aufmerksamkeitsprüfung. Psytest 